\title{
Evolutionism and its Critics
}

\author{
by \\ Stephen K. Sanderson \\ Department of Sociology \\ Indiana University of Pennsylvania
}

\begin{abstract}
v. $2 / 11 / 97$
(C) 1997 Stephen K. Sanderson

Cite: Sanderson, Stephen K. (1997). "Evolutionism and its Critics." Journal of WorldSystems Research 3: 94 - 114.

Evolutionary theories have held a prominent place in the history of the social sciences. Although there are many kinds of evolutionary theories, the essential element that they hold in common is their assumption that history is more than just a series of particular and unique events. On the contrary, the evolutionist assumption is that history reveals a certain directionality in the sense that there are similar processes occurring at similar times, at various points throughout the globe. The best of these theories do not limit themselves to simply describing directional patterns, but go on to provide some sort of model or causal explanation for the observed sequence or sequences.
\end{abstract}

The social sciences, sociology and anthropology in particular, have long enjoyed a lovehate relationship with evolutionary theories of society, with the periods of love alternating with periods of hate in a striking pattern of ebb and flow. The second half of the nineteenth century -- the period when sociology and anthropology were born as social-scientific disciplines -- was overwhelmingly a period of love. Most anthropological thinking, and a large amount of sociological thinking, was evolutionary in nature. In anthropology the two most important evolutionary theorists were Lewis Henry Morgan (1974[1877]) and Edward Burnett Tylor (1871), both among the most important founding fathers of that discipline. In sociology there was, of course, Herbert Spencer (1972), whose evolutionism is very familiar to sociologists even today. There were many other evolutionists in both disciplines during this period, and even thinkers whose main contributions were not evolutionary in nature commonly held deep, and often implicit, evolutionary assumptions. In this regard, I am thinking especially of Emile Durkheim. Anyone familiar with his The Division of Labor in Society (1933[1893]) cannot help but notice his strong, and completely unquestioned, evolutionary assumptions about the progress from mechanical to organic solidarity.

[Page 94]

Journal of World-Systems Research

But by the last decade of the nineteenth century things had begun to change. In anthropology, evolutionism began to fall into disrepute at the hands of Franz Boas (1932, 
1940) and his disciples, who dominated anthropological thinking until the 1930s. Boas thought that evolutionism was flawed in many ways. Boas was an extreme historical particularist, or what many sociologists today call a historicist. He argued that neither history nor cultures had any patterns at all. Every culture was just a polyglot of shreds and patches put together largely by culture contact and diffusion. Each culture had its own unique structure and its own unique history. Generalizing about either history or culture was foolhardy in the extreme, if not utterly impossible.

Although evolutionary thinking was strongly criticized during this period, we should not assume that it was absent. Indeed, it was embraced in the 1920 s by such prominent sociologists as William Graham Sumner and his disciples (Sumner and Keller, 1927). But evolutionary thinking had acquired a bad reputation among many of the intellectual leaders of anthropology and sociology (especially the former) and the students of these leaders recognized that to think evolutionarily was to risk one's intellectual career.

Nevertheless, evolutionism survived. The first stirrings of this revival came in the $1930 \mathrm{~s}$ in the hands of V. Gordon Childe $(1936,1951,1954)$, an Australian who became a famous archaeologist working in Scotland. Childe argued that history revealed few patterns if we studied it in minute detail; if we stand back and view it from a wider perspective, patterns reveal themselves. Childe was followed in the 1940s by two other would-be evolutionary revivalists, Leslie White $(1943,1945,1949,1959)$ and Julian Steward $(1949,1955)$. White was a maverick, both intellectually and in personally. The story of his career is particularly interesting. He received his doctorate in anthropology at the University of Chicago in the late 1920s, and many of his professors were fervent disciples of Boas. Naturally, he was taught that evolutionism was basically worthless and that the works of the evolutionists were not worth reading. Not surprisingly, he absorbed these ideas, and thus started his career as a strong anti-evolutionist. But, for some reason, White began to read the works of Morgan and Tylor a few years after finishing his Ph.D. As White tells the story, he was stunned, for these scholars were nothing like what he had been taught. They were far more sophisticated than he had ever imagined, and he felt they hardly deserved the strong criticism that they had received. As a result of this experience, realized that he could no longer defend the Boasian critique of evolutionism, nor teach it to his own students. White became in the 1930s a fervent evolutionist, a position which he defended the rest of his life.

[Page 95]

Journal of World-Systems Research

Along with Childe and Julian Steward, White not only resurrected evolutionary theory, but played a major role in bringing about what I have called the second generation of the evolutionary revival. In the $1950 \mathrm{~s}$, and especially in the $1960 \mathrm{~s}$, evolutionism became not only respectable in anthropology, but actually a major perspective. The most important evolutionists in this period were, in anthropology, Marvin Harris $(1968,1977,1979)$, Robert Carneiro (1970, 1973), Marshall Sahlins (1958, 1960, 1963), and Elman Service 
$(1960,1962,1975)$, all of whom were students of either White, Steward, or both. In sociology, which had, by this time, become almost hermetically sealed off from anthropology, these ideas had little influence--indeed, were probably largely unknown-but evolutionism was revived there by such thinkers as Talcott Parsons and Gerhard Lenski. Lenski was actually one of the few sociologists to be strongly influenced by anthropology, and the evolutionary model he formulated in his major work on stratification, Power and Privilege (1966), and in his textbook Human Societies (1970), was very similar to White's. With Parsons, the situation was quite different. Stung by the criticism that his structural-functional model was incapable of dealing with social change, Parsons responded by writing two short books $(1966,1971)$ in which he formulated an extremely ambitious evolutionary interpretation of the past 5,000 years of human history. As we shall see in more detail later, this theory is strikingly different from currently dominant evolutionary in anthropology at this time. It seems to me that it is one of our poorest evolutionary theories, and perhaps the contemporary theory most vulnerable to the charges of today's evolutionism critics. I shall return to look at it later.

[Page 96]

Journal of World-Systems Research

The second generation of the evolutionary revival had begun to burn out by the late 1970 s, in both anthropology and sociology. Today anti-evolutionism is rampant in both fields. Both fields seem to be beating a hasty retreat to a modern version of Boasian historicism, arguing that history reveals few if any directional patterns and that we must be extremely cautious about generalizations. In sociology, Weberians like Randall Collins (1986) and Michael Mann (1986) are highly suspicious of evolutionary thinking, as are most Weberians. They are hardly alone. In anthropology, the situation may be even worse. This conclusion is suggested to me by a personal incident. In $1990 \mathrm{I}$ published a book entitled Social Evolutionism, which was a critical dissection and evaluation of evolutionary theories in the social sciences over their entire history. The book was reviewed favorably in the American. Joumal of Sociology, and received mixed reviews in Contemporary Sociology and Social Forces. I kept waiting to see a review in the American Anthropologist, but my wait was in vain. I finally contacted the journal's editor about the matter, and she replied that the book review editor had not felt that my book was worthy of review. You could have knocked me over with a feather. I was stunned, and plenty angry too. I was being told that a book devoted to undertaking a full-scale critical examination of one of the most important types of theory in the field of anthropology did not deserve to be reviewed. To me, this was just unimaginable. I couldn't believe it. But in retrospect, perhaps I should have known. I knew that evolutionism had become much less popular among anthropologists, but I greatly underestimated the depths to which that discipline had sunk.

[Page 97]

Journal of World-Systems Research 
Recently one of my students and I conducted a survey of members of the Theory Section of the American Sociological Association concerning their theoretical preferences and their views on a variety of matters. They were queried about evolutionary theories, and their responses give us a bird's eye view of current sociological views of evolutionism. A mere three (3) percent of the theorists thought that evolutionary theories were fundamentally sound and undeserving of the criticism they had received, whereas 38 percent of the respondents thought that these theories were seriously flawed and should be abandoned. The remaining respondents who voiced an opinion ( 47 percent) thought that evolutionary theories were sound in principle, but that they needed considerable modification and improvement.

These findings certainly show the degree of skepticism among today's sociological theorists about evolutionary theories, just as impressionistic evidence has suggested to us, but at the same time they are cause for some optimism. Half of the respondents are willing to endorse an evolutionary perspective at least in principle, even though the vast majority of these believe that current evolutionary theories will not do the trick. (By the way, I place myself within the 47 percent who see evolutionism as sound in principle but as needing improvement. In fact, since I am a member of the Theory Section and answered the questionnaire, this was my answer.) This gives me hope that evolutionary thinking in sociology will once again become popular in the future. I shall return to this point at the end of the paper when I consider the question as to why the popularity of evolutionary theories has ebbed and flowed so dramatically over time.

But what is it, exactly, that critics of evolutionism object to in this form of social theory? Let me take up and respond to six different criticisms:

1. It has frequently been charged that evolutionary theories are illegitimate because they explain history and social change teleologically, thus conceiving history as nothing but the unfolding of predetermined patterns toward some ultimate goal. My own reading of evolutionary theories is that this criticism, while not entirely wrong, grossly overstates its case. The classical evolutionists of the second half of the nineteenth century often seemed to employ this kind of model of change, but I think it has largely disappeared since that time, and I don't think that either Marx or Engels in their version of evolutionism ever held such a view. Virtually all forms of evolutionism in the twentieth century have abandoned such thinking in favor of looking at social evolution as the outcome of particular conditions operating at particular times in the lives of particular individuals. (The most striking exception may be Parsons's version of evolutionism.) In other words, evolutionists attempt to explain social evolution in terms of simple causal models.

[Page 98]

Journal of World-Systems Research 
2. It is often asserted that evolutionary theories have a strong endogenous bias, i.e., that they look at evolutionary events as occurring entirely within societies and fail to consider the role of various external influences, such as diffusion or political conquest. Leslie White took up this criticism in the 1940s with respect to the evolutionism of Morgan and Tylor and showed it to be manifestly false: both Morgan and Tylor, in fact, gave diffusion an important role in the evolutionary process itself. And more recent versions of evolutionism, while perhaps more endogenist than exogenist, usually leave plenty of room for the role of external factors. Moreover, as I shall argue below, world-systems analysis, which is extremely notable for its criticism of purely endogenist models of change, is in fact a version of evolutionism.

3. Critics of evolutionary theories such as Giddens $(1981,1984)$ and Irving Zeitlin (1973) have objected to them on the grounds that they employ a specious concept of adaptation. This objection seems to be rooted in the notion that the concept of adaptation is incurably functionalist and, since both thinkers object to functionalism, this makes evolutionary versions of functionalism highly suspect. It must be conceded that some versions of evolutionism do employ a functionalist notion of adaptation. This is most apparent in Parsonian evolutionism, in which it is societies that do the adapting, and these societies evolve toward continually higher degrees of "adaptive capacity." But the concept of adaptation can be reformulated so that it is individuals rather than societies that do the adapting, and so those notions that perceive evolution as producing increasing adaptive capacity are cut away. In fact, I shall argue that there are current evolutionary theories that do precisely that.

[Page 99]

Journal of World-Systems Research

4. Many critics also object to evolutionary theories for being inherently progressivist, i.e., for assuming that social evolution is tantamount to one or another form of improvement in the human condition. When I first began my survey of evolutionary theories, I expected to find that this assumption was true of early evolutionary theories but that it has been discarded in the twentieth century. But I turned out to be wrong. In fact, the vast majority of evolutionary theories are progressivist, some of them strongly so. The question then remains as to whether progressivism is justified by the actual historical record. My view is that this is an extremely complicated question which permits of no easy or simple answer. History is really a mixed bag in which some things have become better and others become worse, and the answer also depends on whether you are looking at social evolution over its entire course or simply at some phases of it. For example, it matters a great deal whether you are talking about social evolution before the rise of capitalism in the sixteenth century or social evolution since that time. But the real issue is whether evolutionary theories are inherently progressivist, i.e., whether or not they must be such. And the answer to this 
question is no, there is no inherent association between evolution and progress. The best example of this is the work of the anthropologist Marvin Harris, who has formulated an evolutionary theory that, while viewing history as a mixed bag, is often anti-progressivist, and his anti-progressivism is backed up with striking empirical data. I have tried to develop my own version of evolutionism directly on the basis of Harris's model.

5. Anthony Giddens, one of the leading anti-evolutionists in sociology today, has made a special point of criticizing evolutionary theories for their lack of any concept of human agency, which for Giddens completely invalidates any social theory. In Giddens's view, evolutionary theories are hard forms of determinism that see individuals as just the playthings of blind social forces. My reading of evolutionism, or at least of the best current evolutionism, is quite different. I see the best current evolutionary theories as clearly implicating the individual and his or her choices in social evolution. For example, what was going on in the first great evolutionary transformation, the Neolithic Revolution, which brought agriculture and agricultural communities into the world? My answer, based on the work of many anthropologists and archaeologists, is that individuals were making choices about shifting toward a new mode of production in terms of their various interests: the standard of living they wanted to enjoy, the amount of time and effort they wanted to expend in making a living, and so on. The Neolithic Revolution was a human creation, just as later evolutionary transitions were. No one was reacting blindly to unseen social forces. Agency and structure were intertwined. Now, of course, the notion of agency I am employing here is one that sees individuals as making choices within the context of a set of constraints, and thus these choices are not truly voluntaristic, which may cause Giddens to object that this is no real concept of agency at all. But to my mind it is. It is just what Marx was talking about when he declared that "Men make history, but they do not make it exactly as they please."

[Page 100]

Journal of World-Systems Research

6. But perhaps the biggest objection to evolutionary theories today, especially among sociologists, is that they impute far too much directionality to the flow of history. Weberian sociologists like Collins (1986) and Mann (1986), for example, see history in terms of particularity and the general absence of definable patterns. This is perhaps the hardest of all the criticisms of evolutionism to respond to. In his famous critique of evolutionism written over a quarter of a century ago, Robert Nisbet (1969) said that the detection of historical pattern is not a property of history itself, but is simply in the eye of the beholder. To a large extent this is correct, but Nisbet doesn't play fairly. He claims that pattern is in the eye of the beholder, but that the absence of pattern apparently isn't. It is just the way things are! But how can that be so? I would argue that both patterns in the form of directionality and historical uniqueness, are fundamental parts of the historical 
record. Some scholars seem more attuned to one, others more attuned to the other, for reasons that we don't fully understand. This seems to be like one of those Gestalt drawings where first you see a woman's face, and then you see a candlestick rather than the face, and then you see the face again. My point is simply this: Why not play it both ways and recognize that pattern and unique event are there to be observed? Why deny the one in order to embrace the other? Evolutionists don't deny the existence or the importance of historical uniqueness and divergence, but simply try to discern directional patterns that may be, let's face it, a lot harder to pick out.

[Page 101]

Journal of World-Systems Research

(As an aside it is interesting to see how critics of evolutionism sometimes become, in spite of themselves, evolutionists of a sort. In his famous book The Sources of Social Power [volume 1, 1986], Michael Mann argues against evolutionary interpretations of history, at least with respect to the last 5,000 years. However, one of his major points in his book involves the steady concentration of power over time, or increasing power capacity, and he spends a lot of time talking about how this has come to be so. That looks pretty much like a type of evolutionary argument to me. Also, consider Anthony Giddens, an even more severe critic of evolutionism. Giddens's own alternative to evolutionism is a theory of what he calls increasing time-space distanciation. Take a look at this theory as it is spelled out in several of his books [e.g., 1981, 1984]. If it's not a theory of directional social change, and thus a version of evolutionism, I don't know what it is. The reason that Giddens thinks it is non-evolutionary is because he doesn't have a very good understanding of what an evolutionary theory actually is. Why that should be, I examine below.)

To return to the main theme, let me just say that I don't see how the broad features of human history can be viewed except in evolutionary terms. Most of my recent book Social Transformations (Sanderson, 1995) is devoted to outlining and explaining the three greatest transformations of world history: the Neolithic Revolution beginning some 10,000 years ago, the evolution of civilization and the state, beginning some 5,000 years ago, and the beginnings of the modern capitalist world some 500 years ago. The Neolithic Revolution occurred in at least six (and probably eight) different parts of the world at remarkably similar times, and the outcomes were strikingly similar in each case. The same can be said for the rise of civilization and the state. The modern capitalist world can be dated to about $\mathrm{AD} 1500$, and was to a large extent a European phenomenon, although Japan provides a strikingly parallel case, and in fact much of the world was evolving in a more capitalistic direction after about AD 1000 (McNeill, 1982; Modelski and Thompson, 1996). Nor should we overlook the long time period between about $3000 \mathrm{BC}$ and $A D$ 1500. All over the world during this time we find striking directional trends in the form of population growth, technological change, increasing commercialization, increases in the size and scope of political empires, and even ideological changes. These 
changes, which to me are highly deserving of the name evolutionary, were fundamental in setting the stage for the events after AD 1500 (Sanderson, 1995).

[Page 102]

Journal of World-Systems Research

If I am right in my defense of evolutionism against its critics, then an obvious and crucial question arises: How have these critics gone wrong? What has led them astray? Let me suggest two basic reasons, although there are very likely others. The first reason involves the very nature of the sociological enterprise as it has come to be defined in the second half of the twentieth century. Most sociologists, as we know, are pretty ahistorical, but even so-called historical sociologists have what I believe is a serious limitation: they are concerned with very small slices of time. I think it is often difficult for such sociologists to appreciate the value of evolutionary theories, because such theories are normally concerned with extremely long periods of time.

The second reason, and I strongly suspect the more important of the two, is that the critics have a remarkably incomplete awareness of the broad range and variety of evolutionary theories. Some sociologists, when they think of evolutionary theories, seem to think only of the classical evolutionists. Many others seem to think that evolutionary theory is some sort of unitary model, and the model they have in mind is either Parsonian evolutionism or some derivative thereof. But much more than this is going on, and evolutionary theories can be more different from each other than similar. For example, in his The Constitution of Society (1984), Giddens's discussion of evolutionary theories focuses almost exclusively on Parsons, and other types of evolutionary theory are barely mentioned.

[Page 103]

Journal of World-Systems Research

There are at least two fundamentally different types of evolutionary models, although there are others, and the differences within each of these two types are often very significant. The first of these types is essentially a functionalist sort of evolutionism, represented by the anthropologist Elman Service, but best by Parsons. In my Social Evolutionism (1990), I devote a whole chapter to describing and criticizing Parsonian evolutionism. I find it objectionable in many ways. It misuses the concept of adaptation by assuming that it is societies (rather than individuals) who do the adapting, and it boldly asserts that societies continually strive for higher and higher levels of adaptation, thus making it not only strongly progressivist, but teleological as well. When Parsons does depart from his teleological mode of reasoning and seek to identify actual causes of evolutionary changes, he constantly falls back on idealist assumptions. Parsons proclaims that his theory is a big improvement over those of the classical evolutionists, but this 
claim is dubious. Even Herbert Spencer, of whom Parsons is highly critical, did much more in the way of identifying a range of causal forces in evolution than Parsons does. A careful reading of Parsonian evolutionism will show that it is a modernized and updated version of Hegel's philosophy of history--and hardly any more palatable.

So much for the bad news. The good news is that there is another very different type of evolutionary model, which is the materialist model that passes from Childe, White, and Steward down through Carneiro and Harris. In my extension and formalization of Harris's model (Sanderson, 1995), which I call evolutionary materialism, the leading features of the Parsonian functionalist evolutionary model are gone. This model reconceptualizes adaptation as the striving of individuals to reach their goals and satisfy their interests, and there is no suggestion that societies achieve higher levels of ad aptive capacity as they evolve. The model is explicit in its claim that imputing progress to social evolution is always problematic; whether progress or regression is occurring is always an empirical question that must consider the historical time period and the particular dimension of social life. Most importantly, evolutionary materialism is explicitly anti-teleological; evolution is simply the response of particular individuals located at a particular point in time and space to the conditions that they face. Evolution over the longest periods of time is the sum total of these responses. Plenty of room is given to a variety of evolutionary responses, i.e., no assumption is being made that social evolution is a unitary, purely unilinear process. It involves not only parallel lines of change undergone by different societies, but divergent evolution as well.

[Page 104]

Journal of World-Systems Research

Evolutionary materialism as I have formulated it is a very broad theoretical strategy that allows room for a variety of more specific theories. It includes theories that are ordinarily not thought of as evolutionary and placed under that conceptual umbrella. I have specifically in mind world-system theory as formulated by Immanuel Wallerstein. I regard, and I believe Wallerstein regards, his approach as a type of evolutionary perspective (Sanderson, 1991). It is just that the unit that is doing the evolving is a complex network of societies, what Wallerstein has called a world-system. Wallerstein (1979) has made it clear that he is not trying to oppose his framework to an evolutionary one, but rather to oppose one type of evolutionary framework to another (this other being functionalist evolutionism and modernization theory). Christopher Chase-Dunn and Thomas D. Hall (1997) have developed a modified form of world-systems analysis that can apply to a much longer period of social evolution than Wallerstein has considered. Andre Gunder Frank and Barry Gills (1991) have done something similar by positing that the world system began not in $\mathrm{AD} 1500$ but in $3000 \mathrm{BC}$, and that it has been evolving for these past 5000 years under the directive impetus of capital accumulation.

There are, of course, other types of evolutionary models, quite a few of them in fact. Some people, for example, have tried to develop Darwinian models of social evolution 
(Campbell, 1965; Langton, 1979; Runciman, 1989), an approach I think is somewhat misguided and doesn't take us very far. And there have been a number of attempts from non-academic to present extremely progressivist models that can be explicitly used to guide the evolutionary process from here on out, attempts that I consider highly dubious. But space does not allow consideration of these. The point I am making is simply that evolutionism comes in various colors and shades, and we shouldn't condemn the whole because of the sins of some of its parts. Just as a rose is not a rose is not a rose, evolutionism is not evolutionism is not evolutionism.

[Page 105]

Journal of World-Systems Research

In concluding, I want to consider the question as to why the response to evolutionary theories has shown such an up and down pattern over the past century and a half. Why is evolutionism popular at some times but unpopular at others? To answer this ques tion, I would like to draw on two important concepts from world-system theory, A and B phases and hegemony cycles. A and B phases are the economic expansion and contraction phases, respectively, of Kondratieff waves, an economic phenomenon postulated by the Soviet economist Nikolai Kondratieff (1984[1928])in the 1920s and since appropriated by a variety of scholars, world-system theorists in particular. The ebb and flow of responses to evolutionism seems to have a close association with Kondratieff waves. $T$ he $A$ and $B$ phases of Kondratieff waves since 1850 , the real beginning of social evolutionism, may be sketched as follows (Hopkins and Wallerstein, 1979):

\section{A $1850-1873$}

\section{B 1873-1897}

\section{A $1897-1913 / 20$}

\section{B 1913/20-1945}

\section{A 1945-1967}

\section{B 1967-present}

What happens if we try to match these cycles with the ebb and flow of evolutionary thought? The result is a fairly good match: Evolutionism hits its peaks of popularity largely during periods of expansion (A phases) and moves to a trough of unpopularity during periods of contraction (B phases). Evolutionism emerged and became extremely popular during the 1850-1873 A phase (although some major evolutionary works were written somewhat after that time, which probably means that we have to allow for a certain amount of lag of intellectual phases after economic phases). Evolutionism was starting on its first decline during the latter part of the B phase of 1873-1897 (intellectual 
lag again). The next $\mathrm{A}$ phase does not appear to be associated with a revival of evolutionism, clearly an anomaly, but the unpopularity of evolutionism continues through the B phase of 1913/20-1945, which again fits the pattern. And it is during the A phase of 1945-1967 that evolutionary theorizing rose to the peak of its popularity in the twentieth century. It is true that Childe and White wrote their first evolutionary works before 1945, but it was not until after this date that there was a general rise in evolutionary theorizing and in evolutionism's popularity (as late as 1949 Julian Steward was still extremely nervous about offending the anti-evolutionary powers in anthropology, which led him to be very cautious in using the concept of social evolution). We are now living in the latter part of a B phase, and it was precisely during this phase that evolutionism fell from grace again.

[Page 106]

Journal of World-Systems Research

But there's more. Hegemonic cycles seem to be involved, too. According to Wallerstein, there have been three major hegemonies in the capitalist world-economy, Holland (the United Provinces) between 1625 and 1672, Britain between 1815 and 1873, and the United States between 1945 and 1967. The last two of these correspond both to A phases and to the greatest periods of popularity of evolutionary thought. (Note also that the evolutionary thought in each case was produced primarily by intellectuals in the hegemonic country, i.e., by British scholars in the nineteenth century and American scholars in the twentieth.) What is the connection? A phases are periods of widespread popular optimism, whereas B phases are more likely to be associated with pessimism; periods in the world-economy when a hegemon reigns supreme are ones of extraordinary optimism and a feeling that all is right with the world. There is no better example than the A phase of American hegemony, the period between 1945 and 1967. And such historical periods have intellectual consequences. Because of the close linkage in people's minds of the concepts of evolution and progress, A phases, especially when they correspond to a hegemony's control of the world-economy, will be periods during which evolutionary ideas will seem especially attractive. B phases, by contrast, because of the pessimism and malaise they create, will seem unprogressive to many people, and this will carry over in the case of intellectuals, especially the leading intellectuals, to a general skepticism of evolutionary theories with their implication of general human progress.

[Page 107]

Journal of World-Systems Research

If the above is reasonably valid, a prediction is in order. We are now very near the end of a $B$ phase that has been associated with a great deal of pessimism and malaise. This phase is due to come to a close fairly soon, perhaps by the year 2000 . Wallerstein has suggested that the next A phase in the world-economy may be the greatest of all A phases in terms 
of economic productivity and prosperity. The optimistic feelings this phase will undoubtedly induce should lead to a major revival of evolutionary thought. We are in for, I believe, a new phase in the development and widespread acceptance of one of the most important lines of thinking in the entire history of the social sciences. Because of the probable intellectual time lag, this may not occur until some 5 or 10 years after the beginning of the A phase -- in 2005 or 2010 , say, assuming of course that the A phase begins in 2000 . I want to be in on this major intellectual shift right from the beginning.

\section{References}

Boas, Franz. 1932. "The aims of anthropological research."

Science 76:605-13 . 1940. Race, language, and culture. New York: Macmillan.

Campbell, Donald T. 1965. "Variation and selective retention in socio-cultural evolution." In Herbert R. Barringer, George I. Blanksten, and Raymond W. Mack (eds.), Social Change in developing areas: A reinterpretation of evolutionary theory. Cambridge, MA: Schenkman.

[Page 108]

Joumal of World-Systems Research

Carneiro, Robert L. 1970. "A theory of the origin of the state." Science 169:733-38.

1973. "The four faces of evolution." In John J. Honigmann (ed.), Handbook of social and cultural anthropology. Chicago: Rand McNally.

Childe, V. Gordon. 1936. Man makes Himself. London: Watts \& Co. 1951. Social evolution. London: Watts \& Co.

1954. What happened in history. Harmondsworth, UK: Penguin Books.

(First edition 1942.)

Collins, Randall. 1986. Weberian sociological theory. New York: Cambridge University Press.

Durkheim, Emile. 1933. The division of labor in society. Trans. George Simpson.

Glencoe, IL: Free Press.

(Originally published 1893

Frank, Andre Gunder, and Barry K. Gills (eds.). 1991. The world system: 500 years or 
$5,000 ?$

London: Routledge.

Giddens, Anthony. 1981. A contemporary critique of historical materialism. Berkeley: University of California Press.

[Page 109]

Journal of World-Systems Research

1984. The constitution of society. Berkeley: University of California Press.

Harris, Marvin. 1968. The rise of anthropological theory. New York: Crowell. 1977. Cannibals and kings: The origins of cultures. New York: Random

House.

1979. Cultural materialism: The struggle for a science of culture. New York:

Random House.

Hopkins, Terence, and Immanuel Wallerstein. 1979. " Cyclical rhythms and secular trends

of the capitalist world-economy: Some premises." Review 2:483-500.

Kondratieff, Nicholai D. 1984. The long wave cycle. New York: Richardson and Snyder. (Originally published 1928.)

Langton, John. 1979. "Darwinism and the behavioral theory of sociocultural evolution: An analysis." American journal of sociology 85:288-309.

Lenski, Gerhard. 1966. Power and privilege: A theory of social stratification . New York: McGraw-Hill.

York: McGraw-Hill.

Mann, Michael. 1986. The sources of social power. Volume 1: A history of power from the beginning to $A D$ 1760. Cambridge: Cambridge University Press.

[Page 110]

Joumal of World-Systems Research 
McNeill, William H. 1982. The pursuit of power. Chicago: University of Chicago Press.

Modelski, George, and William R. Thompson. 1996. Leading sectors and world powers:

The coevolution of global economics and politics. Columbia: University of South

Carolina

Press.

Morgan, Lewis Henry. 1974. Ancient society, or researches in the lines of human progress from savagery through barbarism to civilization. Gloucester, MA: Peter Sinith. (Originally published 1877. )

Nisbet, Robert A. 1969. Social change and history: Aspects of the Western theory of development.New York: Oxford University Press

Parsons, Talcott. 1966. Societies: Evolutionary and comparative perspectives . Englewood Cliffs, NJ: Prentice-Hall.

1971. The system of modern societies. Englewood Cliffs, NJ: Prentice-Hall.

Runciman, W.G. 1989. A treatise on social theory. Volume II: Substantive social theory. Cambridge: Cambridge University Press.

Sahlins, Marshall D. 1958. Social stratification in Polynesia. Seattle: University of Washington Press.

[Page 111]

Journal of World-Systems Research

1960. "Evolution: Specific and general." In Marshall D. Sahlins and Elman R. Service (eds.), Evolution and culture. Ann Arbor: University of Michigan Press.

1963. "Poor man, rich man, big man, chief: Political types in Melanesia and Polynesia." Comparative studies in society and history. 5:285-303.

Sanderson, Stephen K. 1990. Social evolutionism: A critical history. Oxford: Basil Blackwell.

. 1991. "The evolution of societies and world-systems." In Christopher Chase-Dunn and Thomas D. Hall (eds.), . Boulder, CO. Westview Press.

1994. "The transition from feudalism to capitalism: the theoretical significance of the Japanese case." Review 17:15-55. 
1995. Social transformations: A general theory of historical develop ment. Oxford: Blackwell.

Service, Elman R. 1960. "The law of evolutionary potential." In Marshall D. Sahlins and Elman R. Service (eds.), Evolution and culture. Ann Arbor: University of Michigan Press. 1962. Primitive social organization: An evolutionary perspective. New York: Random House. 1975. Origins of the state and civilization. New York: Norton.

[Page 112]

Journal of World-Systems Research

Spencer, Herbert. 1972. Herbert Spencer on social evolution. Edited by J.D.Y. Peel. Chicago: University of Chicago Press.

Steward, Julian H. 1949. "Cultural causality and law: A trial formulation of the development of early civilizations." American Anthropologist 51:1-27. 1955. Theory of culture change. Urbana: University of Illinois Press.

Sumner, William Graham, and Albert Galloway Keller. 1927. The science of society. 4 volumes. New Haven, CT: Yale University Press.

Tylor, Edward Burnett. 1871. Primitive culture: Reseurches into the development of mythology, philosophy, religion, language, art, and custom. 2 volumes. London: John Murray.

Wallerstein, Immanuel. 1979. The capitalist world-economy. New York: Cambridge University Press.

White, Leslie A. 1943. " Energy and the evolution of culture." American Anthropologist. 45:335-56.

1945. "History, evolutionism, and functionalism: Three types of interpretation of culture." Southwestern journal of anthropology. 1:221-48.

[Page 113]

Journal of World-Systems Research 
. 1949. The science of culture. New York: Grove Press.

1959. The evolution of culture. New York: McGraw-Hill.

Zeitlin, Irving M. 1973. Rethinking sociology: A critique of contemporary theory.

Englewood Cliffs, NJ: Prentice-Hall.

[Page 114]

Joumal of World-Systems Research 